\title{
Skin burn related to pulse oximetry during photodynamic therapy using talaporfin sodium
}

\author{
Yuka Ino ${ }^{1^{*}}$ D, Midori Nakashima' ${ }^{1}$, Tomonori Morita², Yoko Hori' ${ }^{1}$, Hiroaki Kishikawa', Nobutoshi Hagiwara ${ }^{3}$, \\ Takeshi Matsutani ${ }^{3}$, Tsutomu Nomura ${ }^{3}$ and Atsuhiro Sakamoto ${ }^{1}$
}

Keywords: Photodynamic therapy, Talaporfin sodium, Skin phototoxicity, Skin burn, Pulse oximetry

\section{To the editor}

Photodynamic therapy (PDT) is a less invasive cancer treatment [1]. One of the complications of PDT is phototoxicity because of the photosensitizer [2]. Recent clinical studies showed that no skin phototoxicity was observed during or after PDT using talaporfin sodium for esophageal cancer $[3,4]$.

A 58-year-old woman with esophageal cancer underwent esophagostomy and chemoradiation. However, the cancer grew extensively. PDT was scheduled. Talaporfin sodium was intravenously administered before PDT. We planned general anesthesia. Standard monitoring included pulse oximetry (Radical-7, Masimo Corp., Irvine, CA). We attached the pulse oximeter probes (M-LNCS Neo, Masimo Corp., Irvine, CA) to specific digits. We measured peripheral oxygen saturation for $10 \mathrm{~min}$ each, alternating between left and right hand. We decided to change the fingers in 10 min just from experience. The patient underwent laser beam irradiation. Semiconductor laser light of $664 \mathrm{~nm}$ was used. The next day, the patient showed blistering on both digits, on which the pulse oximeter probes had been applied (Fig. 1). The skin burns were treated conservatively and healed spontaneously for 2 weeks without pigmentation.

Whether PDT is performed under general anesthesia or sedation depends on each surgeon's decision. In our institution, PDT under general anesthesia was selected for the stable operation field. The technique of pulse oximetry is based on the principle that oxygenated hemoglobin and deoxygenated hemoglobin absorb red and near-infrared light differently [5]. The MASIMO pulse oximeter probe emits red light at $660 \mathrm{~nm}$ and infrared light at $940 \mathrm{~nm}$. Moreover, talaporfin sodium has a longer absorption at $664 \mathrm{~nm}$, and the laser light of $664 \mathrm{~nm}$ activates talaporfin sodium as an anticancer drug $[3,4]$. Both the red light emitted by pulse oximetry and the laser light are characterized by the same wavelength zone, leading us to conclude that the blister was photosensitivity dermatitis caused by the red light from the pulse oximeter. All pulse oximeter probes use similar wavelengths. Pulse oximeter sensory associated blisters must occur when using other probes. There were

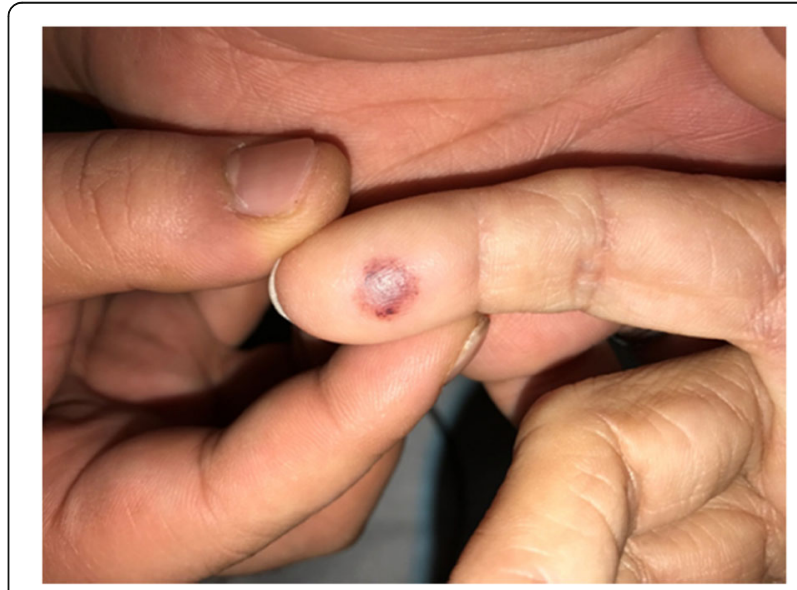

Fig. 1 Blister on the left ring finger where the pulse oximeter had been placed during general anesthesia

\footnotetext{
*Correspondence: yuka-ino@nms.ac.jp

'Department of Anesthesiology, Nippon Medical School, 1-1-5 Sendagi,

Bunkyo-ku, Tokyo 113-8603, Japan

Full list of author information is available at the end of the article
} 
two previous reports of skin burns related to pulse oximetry using photofrin and mTHPC during PDT. Probes were

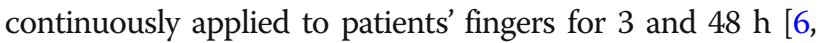
7]. We predicted that shorter exposure time to red light from pulse oximetry would prevent skin phototoxicity. Nevertheless, this case showed that pulse oximetry can cause skin burns regardless of the length of pulse oximetry attachment time and the kinds of photosensitizers. Pulse oximetry is a standard monitor in anesthesia cases to detect hypoxia [5]. The World Health Organization recommends pulse oximetry for all anesthetic patients for perioperative safety [8]. There is no superior monitoring to pulse oximetry for measuring oxygenation, even during PDT. Therefore, we should monitor peripheral oxygen saturation by pulse oximetry as little as possible or intermittently. In future cases, we might need arterial cannulation to assess blood oxygenation, if we will not be able to apply pulse oximetry.

Before PDT, the anesthesiologist should inform the patient regarding the possibility of skin burns related to pulse oximetry.

\section{Abbreviations}

mTHPC: Meta-tetrahydroxyphenylchlorin; PDT: Photodynamic therapy

\section{Acknowledgements}

We would like to thank American Journal Experts (https://www.aje.com/jp/) for English language editing.

\section{Availability of data and materials}

Data from the reported cases will be made available on request.

\section{Authors' contributions}

YI carried out the collection of patient data and drafted the manuscript. MN and TM participated in the anesthetic management. YH and HK drafted and edited the manuscript. AS supervised anesthesiologists. NH, TM, and TN were the doctors in charge and conducted the operations. All authors read and approved the final manuscript.

\section{Authors' information}

YI M.D. is a Staff Anesthesiologist in the Department of Anesthesiology, Nippon Medical School Hospital; MN M.D. is a Staff Anesthesiologist in the Department of Anesthesiology, Nippon Medical School Hospital; TM M.D., PhD., is a Staff Anesthesiologist in the Department of Anesthesiology, Sakakibara Heart Institute; YH M.D., PhD., is a Staff Anesthesiologist in the Department of Anesthesiology, Nippon Medical School Hospital; HK M.D., PhD. is a Director of Anesthesiologists in the Department of Anesthesiology, Nippon Medical School Hospital; NH M.D., PhD., is a staff member in the Department of Gastrointestinal and Hepato-Biliary-Pancreatic Surgery, Nippon Medical School Hospital; TM M.D., PhD. is Associate professor of Gastrointestinal and Hepato-Biliary-Pancreatic Surgery, and Nippon Medical School Hospital; TN M.D., PhD. is Associate professor of Gastrointestinal and HepatoBiliary-Pancreatic Surgery, and Nippon Medical School Hospital; AS M.D., PhD. is Professor and Chair of Anesthesiology, Nippon Medical School.

\section{Ethics approval and consent to participate}

Informed consent was obtained from the patient for publication of this case report. Because this is a case report, the ethical committee in our hospital suggested that there was no need to obtain ethics committee approval.

\section{Consent for publication}

The patient provided written informed consent for the publication of her case history.

\section{Competing interests}

The authors declare that they have no competing interests.

\section{Publisher's Note}

Springer Nature remains neutral with regard to jurisdictional claims in published maps and institutional affiliations.

\section{Author details}

'Department of Anesthesiology, Nippon Medical School, 1-1-5 Sendagi, Bunkyo-ku, Tokyo 113-8603, Japan. ${ }^{2}$ Department of Anesthesiology, Sakakibara Heart Institute, 3-16-1 Asahi-cho, Fuchu-shi, Tokyo 183-0003, Japan. ${ }^{3}$ Department of Gastrointestinal and Hepato-Biliary-Pancreatic Surgery, Nippon Medical School, 1-1-5 Sendagi, Bunkyo-ku, Tokyo 113-8603, Japan.

Received: 7 July 2018 Accepted: 31 August 2018

Published online: 11 September 2018

References

1. Dolmans DE, Fukumura D, Jain RK. Photodynamic therapy for cancer. Nat Rev Cancer. 2003:3:380-7.

2. Yano T, Hatogai K, Morimoto H, Yoda Y, Kaneko K. Photodynamic therapy for esophageal cancer. Ann Transl Med. 2014;2:29.

3. Yano T, Muto M, Yoshimura K, Niimi M, Ezoe Y, Yoda Y, et al. Phase I study of photodynamic therapy using talaporfin sodium and diode laser for local failure after chemoradiotherapy for esophageal cancer. Radiat Oncol. 2012;7:113.

4. Yano T, Kasai H, Horimatsu T, Yoshimura K, Teramukai S, Morita S, et al. A multicenter phase II study of salvage photodynamic therapy using talaporfin sodium (ME2906) and a diode laser (PNL6405EPG) for local failure after chemoradiotherapy or radiotherapy for esophageal cancer. Oncotarget. 2017:8:22135-44.

5. Chitilian H, Kaczka D, Melo MV. Respiratory monitoring. In: Miller RD, Cohen $\mathrm{NH}$, Eriksson LI, Fleisher LA, Wiener-Kronish JP, Young WL, editors. Miller's anesthesia. Philaderphia: Elsevier; 2015. p. 1541-79.

6. Farber NE, McNeely J, Rosner D. Skin burn associated with pulse oximetry during perioperative photodynamic therapy. Anesthesiology. 1996;84:983-5.

7. Radu A, Zellweger M, Grosjean P, Monnier P. Pulse oximeter as a cause of skin burn during photodynamic therapy. Endoscopy. 1999:31:831-3.

8. World Health Organization. Guidelines for safe surgery: 2009: safe surgery saves lives. Geneva: WHO; 2009.

\section{Submit your manuscript to a SpringerOpen ${ }^{\circ}$ journal and benefit from:}

- Convenient online submission

- Rigorous peer review

- Open access: articles freely available online

- High visibility within the field

- Retaining the copyright to your article

Submit your next manuscript at $\boldsymbol{\nabla}$ springeropen.com 